\title{
Imagine a universe An artist's take on Astronomy
}

\author{
Margherita Abbozzo \\ Via San Felice a Ema, 18 \\ 50125 Firenze, Italy \\ email: margherita.abbozzo@gmail.com
}

\begin{abstract}
This is a brief introduction to the ideas behind the art installation Siderea, Homage to Galileo that was created for, and exhibited at the IYA 2009 Opening Ceremony at UNESCO in Paris. The text narrates the attraction that astronomy exercises on the author, who studied Classics before becoming an artist and has always been fascinated by science.
\end{abstract}

Keywords. Art, Galileo, inspiration, Orion, Pleiades, Praesepe

What is an artist looking for when looking at the stars ?

This artist is not looking for definitive answers. I seek connections. Connections that make sense of my transit on this planet, as well as connections that position me in the universe and link me to all the past generations of mortals that have been on the quest for a relationship between micro and macrocosm. We all know that in the last twenty years this ancient ideal has been demolished, reinstated, questioned and updated at a frenetic pace by modern cosmology. For an artist these changes are profoundly inspiring, because the fields new developments inform, sustain and shape the kind of meaningful relationship with the universe that is possible today. These are new frontiers for artists too. Art has always dealt with the idea of the universe, and my work has been profoundly inspired by astronomy from the start.

What exactly is the idea of the universe? While it might be clear to an astronomer, for a lay person it is wonderfully hard to even imagine an universe. To begin with, and leaving aside the question of the universe vs a multiverse, what does infinite exactly mean? Is it possible to visualise something - anything - that has no ends nor any kind of edges? And that possibly expands, twists and loops in more dimensions that I can see or feel? To make it worse: how can anyone imagine a universe that is not only infinite, but that it is also expanding! And then: if the universe is limitless, how can there be star atlases with pages that neatly contain slices of deep infinite? If one has to understand these pages as limited graphic conventions, where does the limit fall, exactly ?

Astronomers are accustomed to these mind-bending problems, while artists are not. Things are complicated by the undeniable fact that astronomy is a difficult discipline to approach as a lay person. Whoever reads astronomy texts soon encounters a barrage of such impossible questions. To continue with some of these: How is one to understand and visualise black energy? Or, can the mind comprehend what 1 million light-years signify? Try to imagine one million light years. Try to visualise the concept. It is possible to understand this idea as a concept. But when you try to scale this down to your human dimensions and visualise it, it becomes a lot less clear. So the next question is: can the human brain understand really understand the kind of information that contemporary astronomy is giving us? I am not sure that my brain can. And this is part of the stupendous attraction of astronomy. In fact, astronomy texts are an exercise in wonder for me, 
an artist who does not hold a scientific degree and at the same time does not abdicate rational powers to a credo or a church.

Black holes, deep universe, plasma, black matter, strings, infrared beams: trying to understand such concepts is one of the most magnificent adventures for the human mind whether you are an astronomer or not. The act of looking into these ideas has the irresistible effect of opening up, before you know it, unknown, scary and wonderful nonEuclidean spaces in ones brain. These non-Euclidean spaces are exactly where art may reside. Because it is in these spaces that astronomy comes in close contact with human brains and hearts, exercising an irresistible gravitational pull. Astronomy probes the unknown to understand mans position in space and time. How can this not inspire whomever deals with visual ideas?

And here is another strange but true fact: astronomy theory is (for me, at least) much more inspiring than the images beamed down from satellites. Somehow, most of these pictures of galaxies, nebulas and stars end up being disappointing and unexciting. Perhaps this is because it is a mechanical eye that is doing the looking. Or maybe it is because of the imaging and the colouring. Human decisions are present here, but it is hard to get excited about a tinted mechanical image of a purple cloud of dust or a pinkish-yellowish ball of gas. In fact, it is a bit like going to an old and faded Luna park with grown up kids: the rides are not that exciting anymore, nobody believes the fire-eater is really, really swallowing the flames and we have already seen the tricks of the distorting mirrors a million times On the contrary it is precisely the very idea of probes floating above our heads, far, far away in space and time, that is truly mesmerizing. The fact that humans managed to do that. The fact that we can shoot, from our small planet, capsules with ultra-sophisticated technology on board and send these capsules further away that we have ever been further away that we can even comprehend: this is true magic.

Man walked on the Moon and will soon walk on Mars. The theory that brought us into space, and the fact that it proved right - all the maths worked, all the physical laws devised by man proved to be correct - is to my mind a million times more exciting than the tinted images of all those blurry red gasses. Astronomy is so fascinating for an artist exactly because it mixes hard calculations and facts, with the impalpable, hard-to-define and-harder-still-to-comprehend stuff of dreams.

Man, I believe, has invented three beautiful utopian dreams in order to make sense of chaos. These are Science, Art and Religion. Each one of us chooses to believe in one of these, according to ones own history, culture, and preferences. Some lucky people might find solace and inspiration in more than one of these. In different ways, all of them put us in touch with our human limits and with always new possibilities. All unlock possible meanings. In my experience, Science, Art and Religion are most stimulating and fecund when they suggest evolving meanings and higher possibilities. When they open up doors, not when they close them shut with myriads lists of laws, rules and regulations. We are here for a short time and in that time we need to be pushed onwards and upwards, we need awe, we need a bigger picture we can relate to. Astronomy does this and has been doing it for centuries. Art does it too, minus the calculus.

I grew up in a household full of scientists, most of them extraordinary women, all of them interested in Galileo's work. Calculus never attracted my interest, but Galileo's ideas, life and accomplishments did. Galileo was a constant presence in my family, a leif-motif always humming in the back of one's consciousness. To paint skies came quite naturally. And not romantic skies à la Van Gogh but factual, scientific skies. The kind of skies that could be glimpsed through astrolabes, for example. Since 1994, I have used these computers of the first millennium to reconstruct what the sky looked like at crucial 
dates in history : to paint the sky over Florence in the spring of the year 1300, when Dante started his journey. Or the sky at dawn the day in October 1492 when someone onboard ship sighted land, America, for the first time. Or again, the sky over Berlin on November 19th, 1989: looking East and looking West. And many other such moments, which have been exhibited in solo shows in London, Amsterdam, Florence, and other cities.

In 1999 some of these works plus a series of new screenprints formed the body of the book Stelle. Libro d'Ore per il Tempo Nuovo (see Abbozzo 1999). In it, two artists the poet Mario Luzi and myself - and two astronomers - Margherita Hack and Franco Pacini - discussed the various possible approaches to the idea of the universe. This book is now in the permanent collection of the Victoria and Albert Museum in London. Astrolabes, navigation systems and space research figure prominently also in a web art work I created for the Italian Navy in 2002. Portolani was a work commissioned by the Navy and it explored the connections between advanced space technologies and art $\dagger$.

My work is based on research, preferably on first-hand sources. One of the most inspirational sources I have ever read is Galileos Sidereus Nuncius. This is of course a fundamental book, both for its revolutionary news and its interesting graphics, where observational sketches mingle with the text. And also, for me, because of its mesmerising drawings. Sidereus Nuncius contains four drawings made by Galileo, who as is well known had also received an artistic education. Each drawing depicts a constellation or part of one: Orion's Belt, The Pleiades, Orion's Nebula, and Praesepe's Nebula. These four images have accompanied me for a long time and formed the core of many of my installations.

One such work, Il Cielo Dentro (or The Sky Inside), was created in 2006 for Galileo's house in Florence. A series of small oil paintings on wood panels, it was exhibited in the rooms where Galileo made some of his observations. Another was Sidereus Nuncius, a large work created for the 2008 Sacred Art Biennale. It was composed by three large wall paintings based on three of Galileo's drawings, which were accompanied by an enormous floor ring made of freshly cut and highly perfumed laurel.

Siderea, Homage to Galileo was created in January 2009 for the official opening of IYA 2009 at UNESCO Headquarters in Paris. The installation occupied a large area in the corner of an exhibition hall and was located in front of a large Mirò mural: it was a wonderful marriage between art and science. Siderea consisted of two large mural paintings, each reproducing one Galilean drawing: Orion's Belt and the Pleiades. In front of these blue doors to the sky, on the floor, lay a large ring made up of astronomy books, which were generously lent by the Société Astronomique de France. The work opened up a space within its space: it was inviting and educational at the same time. It worked well.

All of this IYA2009 inauguration event in Paris has been very successful. It has also been quite different from other similar occasions. And not just because random art events were planned collaterally to the astronomy meetings. Here, in the beautiful UNESCO Headquarters, art and artifacts mixed harmoniously with pure research, as well as with the talks given by the brightest luminaries in the field.

To be able to listen to them was a memorable experience. Sitting in the auditorium was truly moving for me. For as long as I was able to follow the speeches, which is until the discussions became too technical, I had the wonderful experience of feeling my brain and my heart opening up to new, awesome, dizzying perspectives. During the breaks, the very same luminaries and the general public walked around the art exhibition and many

$\dagger$ This work won numerous prizes and can now be seen at www.margheritaabbozzo.com 


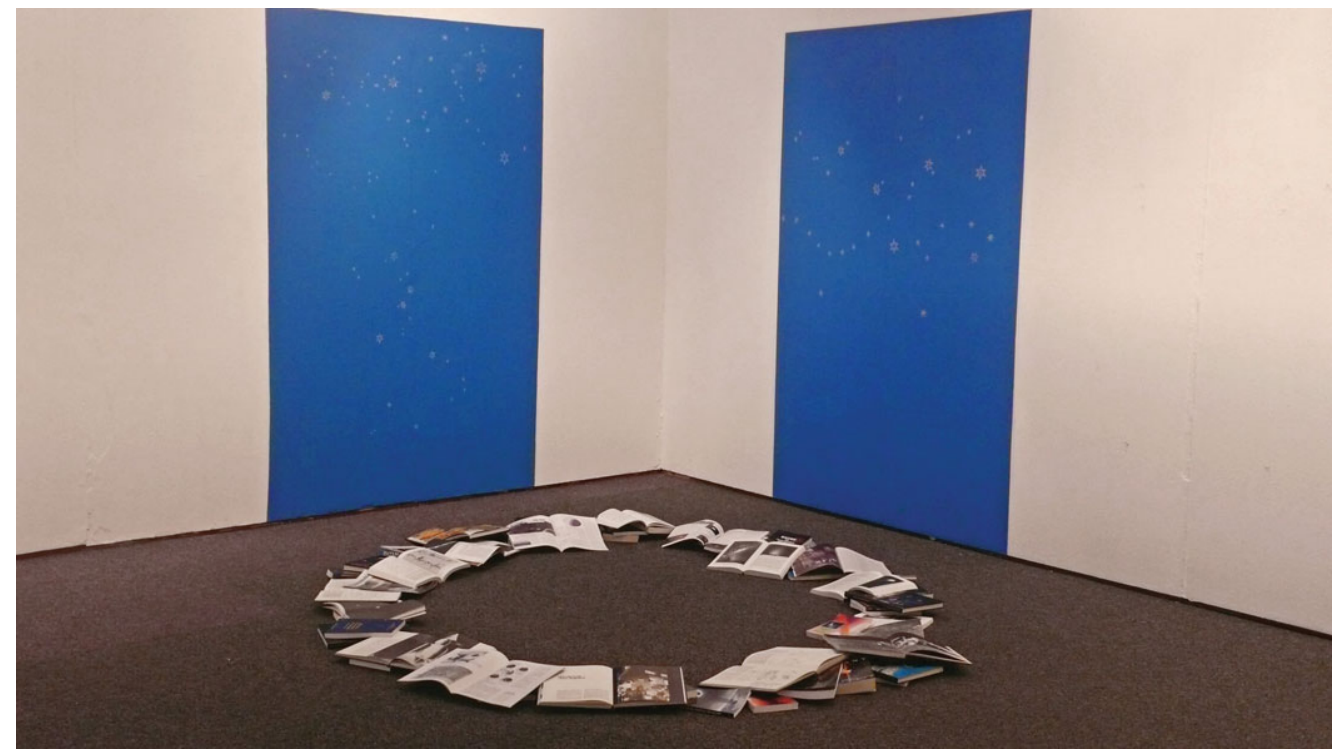

Figure 1. Siderea - Homage to Galileo, exhibited at the Salle Miró, UNESCO Headquarters, Paris 2009 (C) M. Abbozzo).

came to Siderea, attracted by the space it created with its large blue skies, its enchanting drawings of stars and its large circle of books. Most people in the audience were familiar with Galileo's drawings, and their new setting was part of the work's attraction. For me, it was both terrifying and a dream to show my work to an audience composed by many professional astronomers.

Everyone was invited and welcomed to step inside the circle of books, and there was a constant stream of people posing in front of the work for souvenir photos. People were interested in the drawings and in the books.

Siderea gathered together scientists, journalists and lay people, inviting all to look around, marvel at what was there, and feel the solace, connection, awe and happiness that art and astronomy inspire at all times.

\section{References}

Abbozzo, M. 1999, Stelle. Libro d'Ore per il Tempo Nuovo (Firenze: Leo S. Olschki) 